\title{
Sulfonaphthyloxysubstituted Phthalonitriles and Phthalocyanines on their Basis ${ }^{\otimes}$
}

\author{
Vladimir P. Kulinich, ${ }^{@}$ Gennady P. Shaposhnikov, and Rimma A. Badaukaite \\ Department of Fine Organic Synthesis Technology, Ivanovo State University of Chemistry and Technology, Ivanovo, \\ 153000, Russia \\ @Corresponding author E-mail: ttoc@isuct.ru
}

\begin{abstract}
Using the reactions of nucleophilic substitution of bromine in 4-bromophthalonitrile for mono-and disulfonaphthyloxy groups the corresponding substituted phthalonitriles were synthesized and used for the obtaining of tetra (mono- and disulfonaphthyloxy)phthalocyanines and their complexes with cobalt. By the interaction of (mono- or disulfonaphthyloxy)phthalonitriles with unsubstituted phthalonitrile and $\mathrm{CuCl}$ the copper complexes combining substituted and unsubstituted isoindoles fragments in the molecule were obtained. Their solubility in aqueous media is due to the presence of sulfonaphthyloxysubstituents in molecules. The compounds obtained were characterized by element analysis data, IR and electron spectroscopy.
\end{abstract}

Keywords: Sulfonaphthyloxysubstituted phthalonitriles, phthalocyanines, metallocomplexes, synthesis, spectroscopy.

\section{Сульфонафтоксизамещенные фталонитрилы и фталоцианины на их основе ${ }^{\otimes}$}

\author{
В. П. Кулинич, ${ }^{@}$ Г. П. Шапошников, Р. А. Бадаукайте \\ Ивановский государственныцй химико-технологический университет, Иваново, 153000, Россия \\ @E-mail: ttoc@isuct.ru
}

\begin{abstract}
С использованием реакциии нуклеофильного замещеения брома в 4-бромфталонитриле на моно- и дисульфонафтоксигруппы синтезированы соответствующие замещченные фталонитрилы, на основе которых получень тетра (моно- и дисульфонафтокси) фталоцианины и их комплексы с кобальтом, а также комплексы меди, сочетаюшие в молекуле сульфонафтоксизамещенные и незамещенные изоиндольные фрагментыл. Наличие в молекулах сульфонафтоксизаместителей обусловливает их растворимость в водных средах. Полученные соединения охарактеризованы данными элементного анализа, ИК и электронной спектроскопии.
\end{abstract}

Ключевые слова: Сульфонафтоксизамещенные фталонитрилы, фталоцианины, металлокомплексы, синтез, спектроскопия.

\section{Введение}

Среди замещенных фталоцианинов многочисленную группу составляют сульфопроизводные, которые уже нашли применение в качестве красителей $^{[1,2]}$ и катализаторов различных окислительновосстановительных процессов. ${ }^{[3]}$ Эти соединения

\footnotetext{
$\otimes$ This contribution is dedicated to professor Vasilij Fedorovich Borodkin on the occasion of his $100^{\text {th }}$ Anniversary.

$\otimes$ Статья посвящена 100-летнему юбилею профессора Василия Фёдоровича Бородкина.
}

интенсивно исследуются в качестве препаратов при диагностике и терапии злокачественных опухолей. ${ }^{[4]}$ Имеющиеся литературные данные по сульфированным фталоцианинам касаются в основном соединений, в которых сульфогруппы непосредственно связаны с бензольными кольцами фталоцианинового лиганда. Вместе с тем заслуживают внимания производные, в которых они находятся при имеющихся заместителях, в частности, арильных. Число публикаций по таким соединениям весьма ограничено, ${ }^{[5]}$ хотя они представляют интерес для исследования влияния на свойства числа и положения сульфогрупп, удаленных от фтало- 
цианинового макрокольца, а также в связи с поиском путей их практического использования.

Настоящее сообщение посвящено синтезу и исследованию сульфонафтоксизамещенных фталоцианинов, содержащих различное число сульфогрупп.

\section{Экспериментальная часть}

Электронные спектры поглощения полученных соединений регистрированы в области 400 - 900 нм на спектрофотометре Hitachi UV - 2001 при комнатной температуре. B качестве растворителей были использованы ДМСО, вода и 0,5\% водный раствор КОН. Концентрация исследуемых растворов составляла $\approx 10^{-5}$ моль/л. ИК -спектры получены на спектрофотометре Avatar 360 FT - IR в области $400-4000 \mathrm{~cm}^{-1}$ в таблетках КВr. Элементный анализ выполнен на приборе Flash EA CHNS-O Analyzer.

\section{Синтез}

Калиевая соль 4-[(6'-сульфо-2'-нафтил)окси]фталонитрила, IV. Смесь 4-бромфталонитрила (1,04 г, 5 ммоль), калиевой соли 2-гидроксинафталин-6-сульфокислоты (2,62 г, 10 ммоль), карбоната калия (3,32 г, 24 ммоль) и 20 мл ДМФА нагревали при перемешивании до температуры кипения ДМФА и выдерживали в этом режиме в течение 2 ч. После охлаждения диметилформамидный раствор отделяли от осадка неорганических примесей фильтрованием. Растворитель отгоняли под вакуумом. Выделенный фталонитрил подвергали хроматографической очистке на оксиде алюминия I степени активности (элюент ДМФА - вода в соотношении 1 : 1). После удаления элюента вакуумной отгонкой твердый остаток выдерживали в вакуум -сушильном шкафу при $70^{\circ} \mathrm{C}$ до постоянной массы. Выход 1,24 г (64\%), порошок желтого цвета, $\mathrm{T}_{\text {разл. }}>250^{\circ} \mathrm{C}$, хорошо растворимый в воде, в ДМФА. Найдено, \%: C 55,52, Н 2,35, N 7,29, S 7,95. $\mathrm{C}_{18} \mathrm{H}_{9} \mathrm{~N}_{2} \mathrm{SO}_{4}$ K. Вычислено, \%: С 55,67, Н 2,32, N 7,22, S 8,25. ИК $v \mathrm{~cm}^{-1}: 2232(v$ $\mathrm{C} \equiv \mathrm{N}), 1051\left(v_{\mathrm{s}} \mathrm{S}=\mathrm{O}\right), 1106\left(v_{\text {as }} \mathrm{S}=\mathrm{O}\right), 1250(v \mathrm{Ar}-\mathrm{O}-\mathrm{Ar})$.

Дикалиевая соль 4-[(6,8-дисульфо-2'-нафтил)окси] фталонитрила, $\boldsymbol{V}$. Получали по выше приведенной методике, используя (3,80 г, 10 ммоль) дикалиевой соли 2-гидроксинафталин-6,8-дисульфокислоты. Выход 1,50 г (61\%), порошок желтого цвета, хорошо растворимый в воде, в ДМФА. Найдено, \%: С 42,28, Н 1,52, N 5,45, S 12,56. $\mathrm{C}_{18} \mathrm{H}_{8} \mathrm{~N}_{2} \mathrm{~S}_{2} \mathrm{O}_{7} \mathrm{~K}_{2}$. Вычислено, \%: С 42,69, Н 1,58, N 5,53, S 12,65. ИК $\vee$ cM $^{-1}: 2230(v \mathrm{C} \equiv \mathrm{N}), 1042\left(v_{\mathrm{s}} \mathrm{S}=\mathrm{O}\right), 1110\left(v_{\mathrm{as}} \mathrm{S}=\mathrm{O}\right), 1201(v$ Ar-O-Ar).

Тетра-4-[(6'-сульфо-2'-нафтил)окси]фталочианин, $\boldsymbol{V I}$.

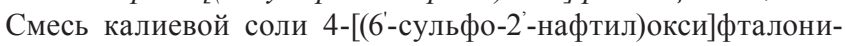
трила $(0,78$ г, 2 ммоль) и карбоната калия $(0,64$ г, 5 ммоль) нагревали при перемешивании до температуры $190-195^{\circ} \mathrm{C}$ и выдерживали в этом режиме в течение 30 минут. Реакционная масса приобретает сине-зеленый цвет. Образовавшийся фталоцианин экстрагировали диметилсульфоксидом и из полученного раствора осаждали добавлением абсолютного этанола. Осадок отфильтровывали, промывали этанолом в аппарате Сокслета. Заключительную очистку осуществляли хроматографированием на силикагеле М 60 (элюент: ДМФА : вода в соотношении $1: 1$ ). После отгонки элюента под вакуумом остаток выдерживали в вакуум-сушильном шкафу при температуре $80^{\circ} \mathrm{C}$ до постоянной массы. Выход 0,50 г (71,5\%), порошок сине - зеленого цвета, растворимый в воде, в смеси ДМФА-вода, в ДМСО. Найдено, \%: С 61,59, Н 3,02, N 7,96, S 9,28. $\mathrm{C}_{72} \mathrm{H}_{42} \mathrm{~N}_{8} \mathrm{~S}_{4} \mathrm{O}_{16}$. Вычислено, \%: С 61,63, Н 3,12, N 7,36, S 8,01. ИК $v \mathrm{~cm}^{-1}: 1040\left(v_{\mathrm{s}} \mathrm{S}=\mathrm{O}\right), 1109\left(v_{\mathrm{as}} \mathrm{S}=\mathrm{O}\right), 1200(v \mathrm{Ar}-\mathrm{O}-\mathrm{Ar})$. ЭСП (ДМСО) $\lambda_{\text {max }}$ нм: 674, 701, 645пл., 612пл.; $\left(\mathrm{H}_{2} \mathrm{O}\right): 606$.

Тетра-4-[(6, 8'-дисульфо-2'-нафтил)окси]фталочиианин,
VII. Получали по выше приведенной методике, используя

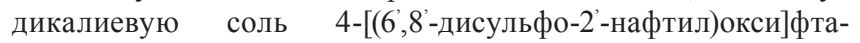
лонитрила (1,01 г, 2 ммоль). Выход 0,49 г (57\%), порошок сине -зеленого цвета, растворимый в воде, в смеси ДМФА -вода, в ДМСО. Найдено, \%: С 50,05, Н 2,41, N 6,45, S 14,81. $\mathrm{C}_{72} \mathrm{H}_{42} \mathrm{~N}_{8} \mathrm{~S}_{8} \mathrm{O}_{28}$. Вычислено, \%: С 50,17, Н 2,44, N 6,50, S 14,87. ИК $\vee \mathrm{cm}^{-1}: 1038\left(v_{\mathrm{s}} \mathrm{S}=\mathrm{O}\right), 1109\left(v_{\text {as }} \mathrm{S}=\mathrm{O}\right), 1228$ ( $v$ Ar-O-Ar). ЭСП (ДМСО) $\lambda_{\max }$ нм: 704, 674, 646пл, 613пл; $\left(\mathrm{H}_{2} \mathrm{O}\right): 638$.

Тетра-4-[(6'-сульфо-2'-нафтил)окси]фталоцианин кобальта, VIII. Смесь калиевой соли 4-[(6'-сульфо-2'-нафтил)

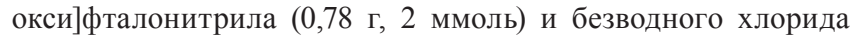
кобальта $(0,065$ г, 0,5 ммоль) нагревали при перемешивании до температуры $190-195^{\circ} \mathrm{C}$ и выдерживали в этом режиме в течение 1 ч. Образовавшийся фталоцианин кобальта из охлажденной реакционной массы экстрагировали диметилсульфоксидом и осаждали из экстракта добавлением абсолютного этанола. Полученный осадок отфильтровывали, промывали этанолом в аппарате Сокслета. Заключительную очистку проводили хроматографированием на силикагеле М 60 (элюент ДМФА/вода в объемном соотношении $1: 1$ ). Выход 0,39 г (54\%), порошок сине -зеленого цвета, хорошо растворимый в воде, в смеси ДМФА-вода, в ДМСО, в водном растворе щелочи. Найдено, \%: С 58,42, Н 2,70, N 7,62, S 8,80. $\mathrm{C}_{72} \mathrm{H}_{40} \mathrm{~N}_{8} \mathrm{~S}_{8} \mathrm{O}_{16}$ Со. Вычислено, \%: С 59,22, Н 2,74, N 7,68, S 8,80. ИК $\vee$ см$^{-1}: 1045\left(v_{\mathrm{s}} \mathrm{S}=\mathrm{O}\right), 1103\left(v_{\text {as }} \mathrm{S}=\mathrm{O}\right), 1205$ ( $v$ Ar-O-Ar). ЭСП (ДМСО) $\lambda_{\text {max }}$ нм: 664, 603пл., $\left(\mathrm{H}_{2} \mathrm{O}\right): 625,680$ инф.

Тетра-4-[(6, 8'-дисульфо-2'-нафтил)окси]фталоиианин кобальта, $\boldsymbol{I} \boldsymbol{X}$. Получали по выше приведенной методике, используя (1,01 г, 2 ммоль) дикалиевой соли 4-[(6,8'-дисульфо2 -нафтил)окси]фталонитрила. Выход 0,53 г (59\%), порошок сине - зеленого цвета, хорошо растворимый в воде, в смеси ДМФА-вода, в ДМСО, в водном растворе щелочи. Найдено, \%: C 48,32, Н 2,20, N 6,23, S 14,43. $\mathrm{C}_{72} \mathrm{H}_{40} \mathrm{~N}_{8} \mathrm{~S}_{8} \mathrm{O}_{28}$ Co. Вычислено, \%: C 48,57, Н 2,25, N 6,30, S 14,39. ИК $\vee$ cm$^{-1}: 1039$ ( $\left.v_{\mathrm{s}} \mathrm{S}=\mathrm{O}\right), 1103$ $\left(v_{\text {as }} \mathrm{S}=\mathrm{O}\right), 1210$ ( $v$ Ar-O-Ar). ЭСП (ДМСО) $\lambda_{\max }$ нм: 673, 613пл; $\left(\mathrm{H}_{2} \mathrm{O}\right): 676,615$ инф.

Примечание: пл. - плечо, инф. - инфлексия.

\section{Результаты и обсуждение}

При получении замещенных фталоцианинов заданного строения, наиболее предпочтительным является их синтез из соответствующих замещенных фталевых кислот или их производных. По сравнению с введением заместителей в предварительно полученные фталоцианины этот метод позволяет избежать примесей веществ, различающихся числом и расположением заместителей. Поэтому нами сначала синтезированы моно- и дисульфонафтоксизамещенные фталонитрилы, исходя из 4-бромфталонитрила (I) в соответствии с приведенной Схемой 1.

Галогензамещенные фталонитрилы являются в настоящее время наиболее популярными субстратами для ароматического нуклеофильного замещения. ${ }^{[6]}$ Имеющиеся в бензольном ядре соединения I электроноакцепторные группы (CN) создают в достаточной степени эффективный положительный заряд на атоме углерода, связанного с атомом брома, что обусловливает его замещение под действием нуклеофильных реагентов, в качестве которых нами использованы:

- калиевая соль 2-гидроксинафталин-6-сульфокислоты (II);

- дикалиевая соль 2-гидроксинафталин-6,8-дисульфокислоты (III). 
<smiles>N#Cc1ccc(Br)cc1C#N</smiles>

Схема 1.

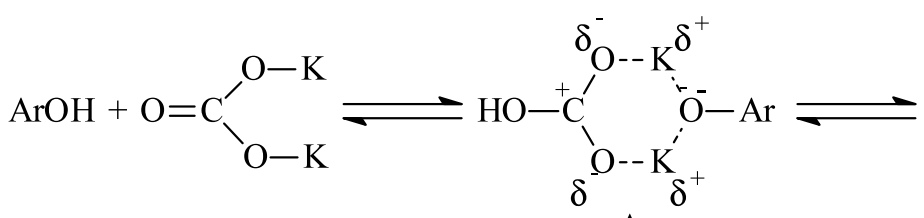

A<smiles>N#Cc1ccc(Oc2ccc(Br)cc2C#N)cc1C#N</smiles>

Схема 2.

Согласно имеющимся представлениям, ${ }^{[7]} \mathrm{S}_{\mathrm{N}} \mathrm{Ar}$ - реакция галогензамещенных субстратов с арилоксисоединениями в ДМФА в присутствии $\mathrm{K}_{2} \mathrm{CO}_{3}$ протекает по следующей Схеме 2:

В начале процесса на поверхности карбоната калия происходит хемосорбция арилоксисоединения, сопровождающаяся его депротонированием и приводящая к образованию реакционноспособного 6-членного комплекса (А). Затем этот нуклеофильный реагент взаимодействует с атомом углерода исходного 4-бромфталонитрила (I), в результате чего образуется $\sigma-$ комплекс (Б). При отщеплении нуклеофуга $\sigma$ - комплекс распадается, а образовавшийся продукт реакции (В) десорбируется с поверхности раздела фаз в диметилформамидный раствор, освобождая поверхность $\mathrm{K}_{2} \mathrm{CO}_{3}$ для новых актов протонирования.

Таким образом, роль $\mathrm{K}_{2} \mathrm{CO}_{3}$ заключается в переводе ароматического гидроксисоединения в биполярный ион, обладающий большей реакционной способностью при нуклеофильном замещении по сравнению с ароматическими гидроксисоединениями.

Время взаимодействия ( $\approx 2$ ч) устанавливали по отсутствию не вступившего в реакцию фталонитрила I. При этом проба реакционной массы практически полностью растворяется в воде.

Диметилформамидный раствор полученных фталонитрилов $(\mathbf{I V}, \mathbf{V})$ отделяли от неорганических примесей $\left(\mathrm{KBr}\right.$ и $\left.\mathrm{K}_{2} \mathrm{CO}_{3}\right)$ фильтрованием, диметилформамид отгоняли под вакуумом при температуре $\approx 90-100^{\circ} \mathrm{C}$. Заключительную очистку соединений $\mathbf{I V}, \mathbf{V}$ проводили хроматографированием на силикагеле M 60, используя в качестве элюента смесь ДМФА-вода в соотношении $1: 1$.
Для подтверждения структуры синтезированных динитрилов IV, V использованы данные элементного анализа и ИК - спектроскопии.

При анализе ИК спектров динитрилов IV, V, представленных на Рисунке 1, и сравнении их с ИК спектром исходного 4-бромфталонитрила (I) необходимо отметить следующее:

- Сохранение характеристической полосы валентных колебаний цианогрупп (2230 - $\left.2235 \mathrm{~cm}^{-1}\right)$, при этом относительная интенсивность этой полосы уменьшается при переходе от моно- (IV) к дисульфонафтоксизамещенному (V) соединению.

- В результате замещения в ИК -спектре исчезает полоса валентных колебаний связей $\mathrm{C}_{\mathrm{Ar}-\mathrm{Br}}\left(645 \mathrm{~cm}^{-1}\right)$ и проявляются новые полосы : 1200-1210 $\mathrm{cm}^{-1}$, относящиеся к валентным колебаниям связи Ar-O-Ar', 1043-1051 см ${ }^{-1}$ - к валентным симметричным, $1150 \mathrm{~cm}^{-1}$ валентным асимметричным колебаниям связи $\mathrm{S}=\mathrm{O}$ в сульфогруппах. ${ }^{[8]}$

- При переходе от моно- к дисульфонафтоксизамещенному фталонитрилу ИК спектр становится менее разрешенным, что можно объяснить усилением межмолекулярного взаимодействия за счет дополнительной сульфогруппы.

С использованием полученных нитрилов IV, V в соответствии с представленной схемой нами синтезированы соответствующие сульфонафтоксизамещенные безметальные соединения VI, VII и их комплексы с кобальтом VIII, IX.

Уже в процессе образования исходных фталоцианогенов IV, V в кипящем ДМФА в присутствии $\mathrm{K}_{2} \mathrm{CO}_{3}$ на стенках реакционной колбы из-за локального перегрева стекла вне раствора было замечено образование веществ синего цвета, которые в дальнейшем после 
Sulfonaphthyloxysubstituted Phthalonitriles and Phthalocyanines on their Basis

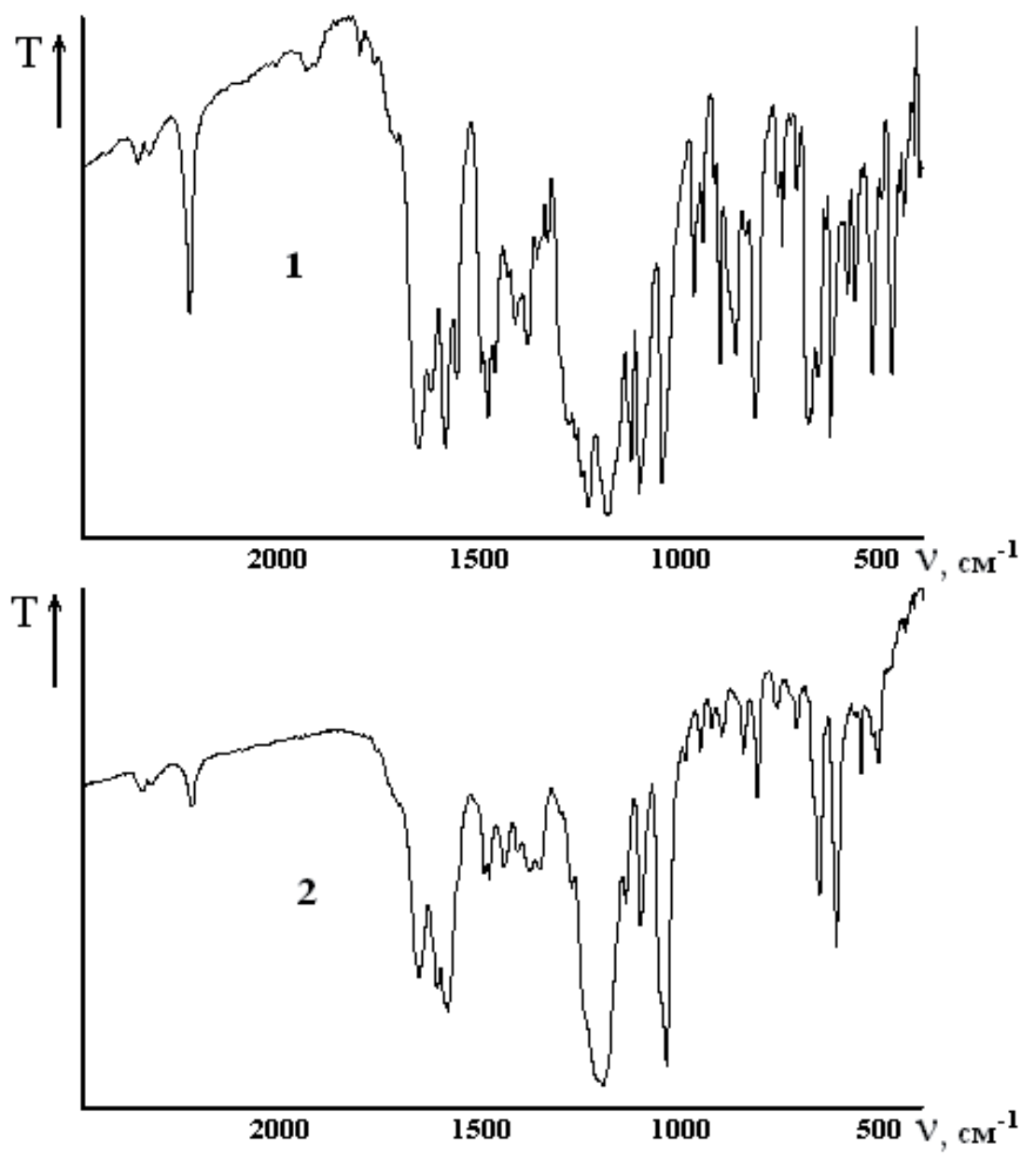

Рисунок 1. ИК спектры динитрилов IV (1), V (2).

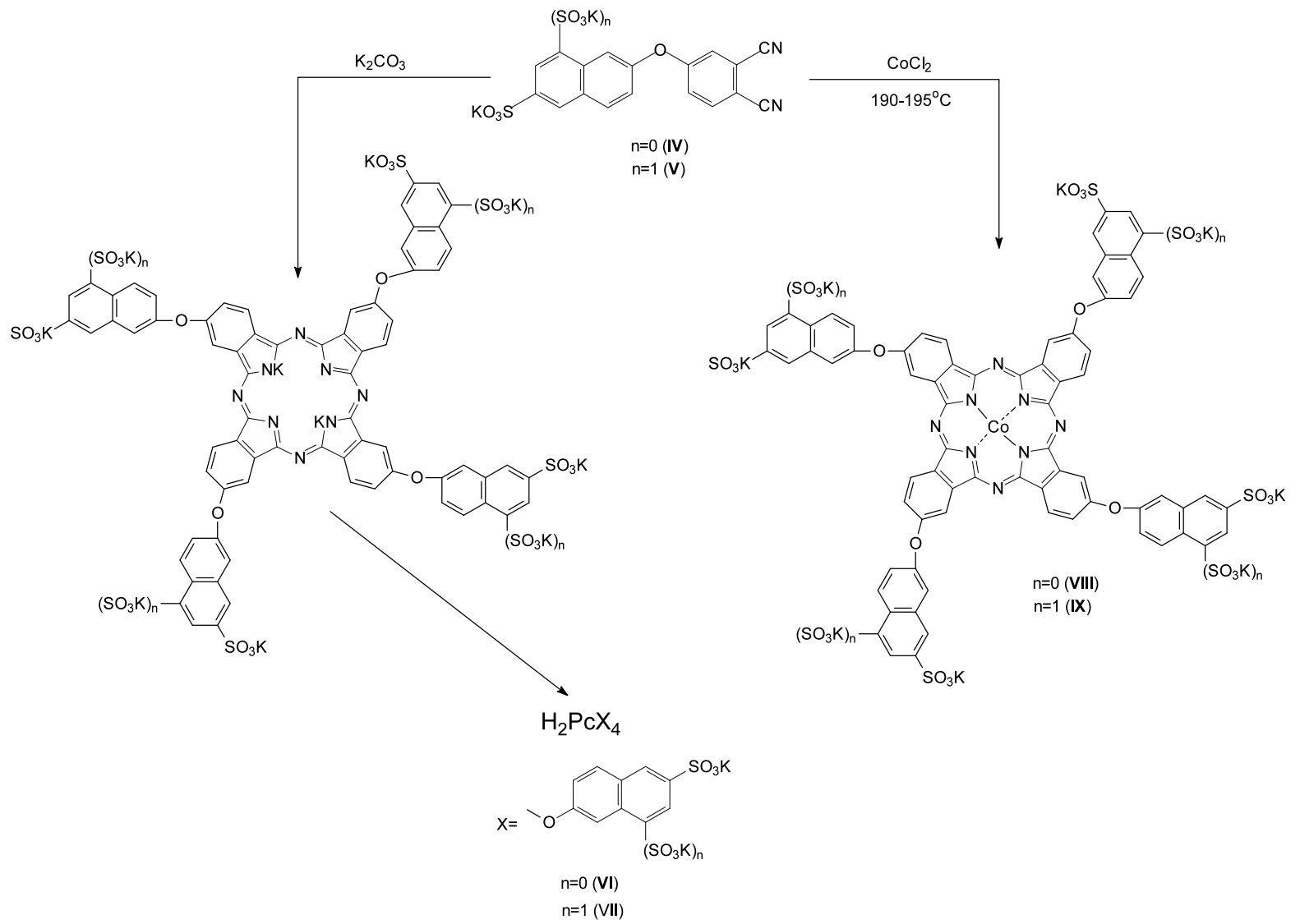

Схема 3. 
выделения идентифицированы как безметальные сульфонафтоксизамещенные фталоцианины (VI-VII).

Анализ литературных данных по синтезу безметального фталоцианина и его структурных аналогов различными методами позволил выделить относительно простой способ, заключающийся в нагревании соответствующих нитрилов с твердой щелочью $\mathrm{NaOH}$, который приводит к образованию целевых продуктов с достаточно высоким выходом. ${ }^{[9]}$

Нагреванием нитрилов IV, $\mathbf{V}$ с избытком $\mathrm{K}_{2} \mathrm{CO}_{3}$ нами осуществлен синтез безметальных соединений VI, VII. Причем, для определения выхода соединений VI, VII по исходным фталоцианогенам, использовались хроматографически очищенные нитрилы IV, V. Для наработки фталоцианинов VI, VII можно использовать фталонитрилы IV, V с неорганическими примесями $\left(\mathrm{KBr}, \mathrm{K}_{2} \mathrm{CO}_{3}\right)$, выделенные из реакционной массы после термовакуумной отгонки ДМФА.

При взаимодействии нитрилов IV, V с безводным хлоридом кобальта при температуре $190-195^{\circ} \mathrm{C}$ в течение $\approx 1$ ч синтезированы соответствующие замещенные комплексы кобальта (VIII, IX). Выделение соединений VI-IX включало извлечение их из реакционной массы диметилсульфоксидом, осаждение из полученных экстрактов добавлением безводного этанола, экстракцию

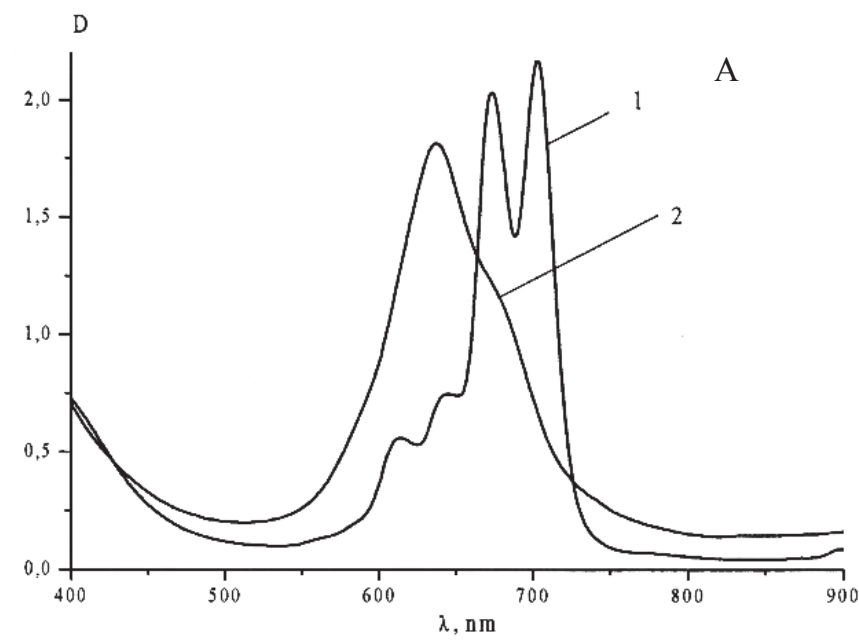

примесей органическими растворителями. Заключительную очистку проводили хроматографией на силикагеле М 60 с использованием в качестве элюента смесь ДМФА-вода в соотношении $1: 1$.

Для идентификации соединений VI-IX использовали данные элементного анализа, колебательной и электронной спектроскопии.

В ИК спектрах безметальных соединений VI, VII следует прежде всего выделить упоминаемые выше при анализе нитрилов IV, V полосы валентных симметричных и асимметричных колебаний связей $\mathrm{S}=\mathrm{O}$ в ароматических сульфокислотах и их солях (соответственно $1039 \mathrm{~cm}^{-1}$ и $\left.1104-1109 \mathrm{~cm}^{-1}\right)$, а также интенсивную уширенную полосу в области 1192-1923 $\mathrm{cm}^{-1}$, относящуюся к валентным колебаний связи Ar-O-Ar'. Интенсивная полоса в области 1000-1050 см-1, характерная для незамещенного безметального фталоцианина, ${ }^{[10]}$ несколько смещена в высокочастотную область.

Электронные спектры поглощения (ЭСП) безметальных соединений VI, VII в диметилсульфоксиде характеризуются наличием 2-х интенсивных полос поглощения в области 674-704 нм. При переходе к комплексам кобальта VIII, IX двухполосный спектр трансформируется в однополосный (664 - 673 нм) (Рисунок 2, Таблица 1.)

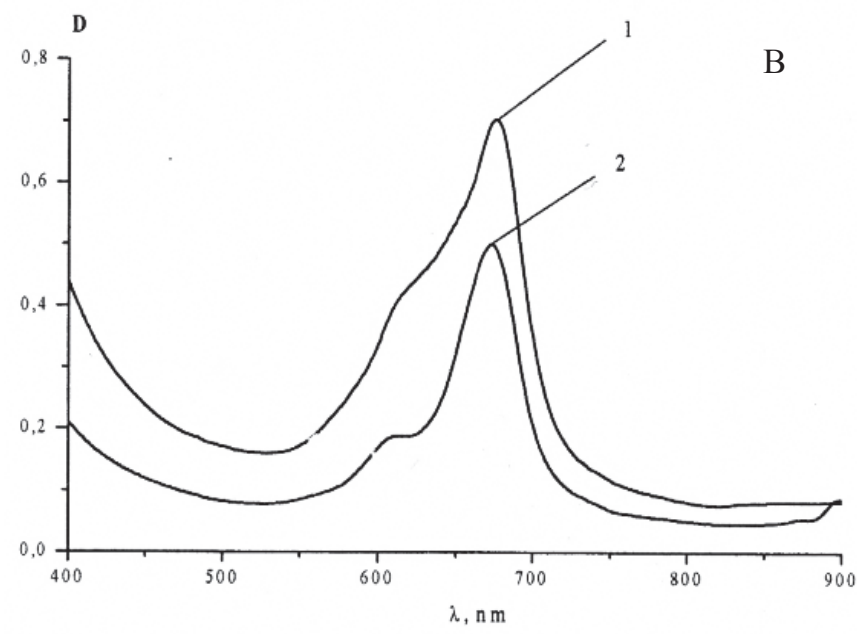

Рисунок 2. Электронные спектры поглощения: А - соединение VII: 1 - в ДМСО; 2 - в воде. В - соединение IX: 1 - в ДМСО; 2 - в воде.

Таблица 1. Положение полос в электронных спектрах поглощения сульфонафтоксизамещенных фталоцианинов VI-IX.

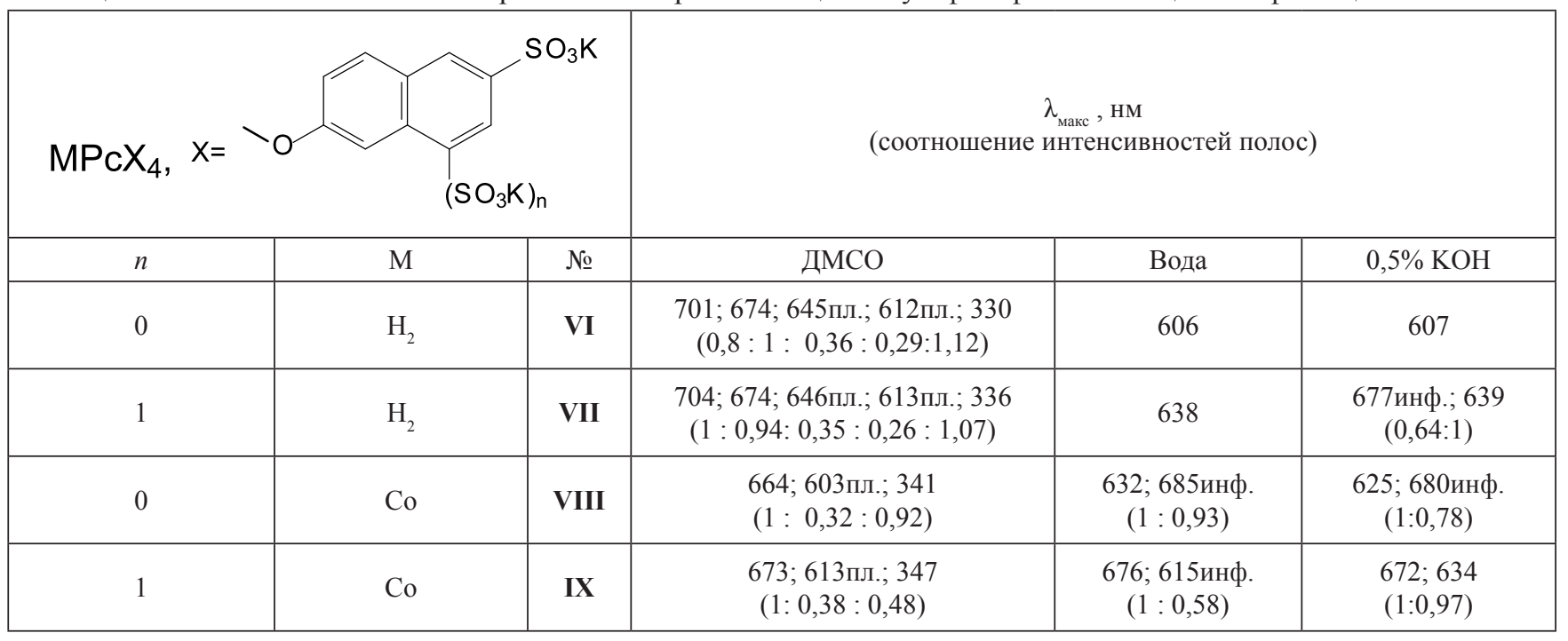


Кроме того, вместо 2-х слабоинтенсивных полос у безметальных соединений VI, VII при 612, 645 и 613, 646 в ДМСО соответственно у комплексов кобальта VIII, IX в указанной области имеется лишь одна (603 и 613, соответственно).

При образовании металлокомплексов с фталоцианиновым и другими макроциклическими лигандами порфиразинового ряда, возникают более высоко симметричные молекулы (симметрия распределения электронной плотности повышается с $D_{2 \mathrm{~h}}$ до $D_{4 \mathrm{~h}}$ ), в результате чего происходит двукратное вырождение электронных уровней и число полос в видимой области сокращается.

Наличие в молекулах синтезированных соединений сульнафтоксизаместителей обусловливает батохромное смещение $Q$-полос на 6-10 нм по сравнению с незамещенными соединениями. ${ }^{[1]}$

В воде и водных растворах щелочей синтезированные соединения, как и известные сульфозамещенные фталоцианины ${ }^{[12]}$ имеют спектры, отличные от диметилсульфоксидных растворов. Все они, за исключением комплекса кобальта с дисульфонафтоксизамещенным фталоцианином, имеют широкие полосы поглощения, максимум которых (606-638 нм) смещен гипсохромно по сравнению с положением Q -полосы в ДМСО. На длинноволновом спаде этой полосы фиксируется инфлексия. Спектр комплекса $\mathbf{I X}$ в воде сохраняет положение $Q$-полосы при 676нм, инфлекция имеется на коротковолновом спаде этой полосы (Рисунок 2, Таблица 1).

Таким образом, вид спектральных кривых, положение максимумов $Q$-полосы зависит от числа сульфогрупп в имеющихся нафтоксизаместителях; состава координационного центра, а также природы растворителей.

Отмеченная особенность спектров характерна для известных сульфозамещенных фталоцианинов и объясняется наличием в растворах ассоциированных и неассоциированных молекул. Согласно данным ${ }^{[13]}$ поглощение при 673 - 704 нм соответствует неассоциированной форме. Появление коротковолновых максимумов и диффузный характер полос в воде и водных растворах щелочей является спектральным проявлениям процессов ассоциации молекул и образования в зависимости от числа сульфогрупп в молекулах

A

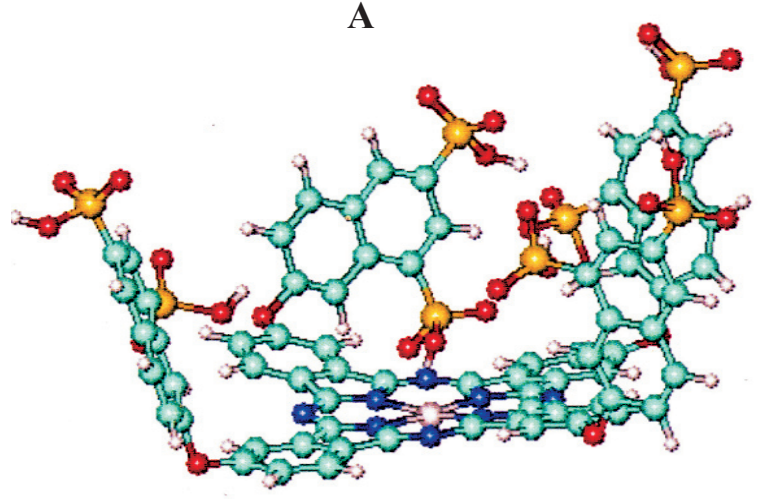

Тетра-4-[(6',8'-дисульфо-2'-нафтил)окси] металлофталоцианин синтезированных фталоцианинов (VI-IX), природы растворителя, концентрации растворов и других факторов, димеров или более крупных ассоциатов, в которых происходит взаимодействие $\pi$-электронных систем соседних макроциклических хромофоров. Это находит отражение в спектральных характеристиках, приведенных в Таблице 1 и на Рисунке 2.

В УФ области (330 - 360 нм) ЭСП синтезированных сульфонафтоксизамещенных фталоцианинов имеется интенсивное поглощение. Соотношение интенсивностей этого поглощения и $Q$-полосы в ДМСО составляет 1,12 : $1-0,92: 1$ (Таблица 1). В воде и водной щелочи в этом диапазоне нет четко выраженного максимума. Как было отмечено нами при анализе ЭСП нафтоксихлорзамещенных фталоцианинов ${ }^{[14]}$ указанное поглощение связано с наложением на слабоинтенсивную полосу Соре поглощения в этой области за счет имеющихся нафтоксигрупп.

Сульфонафтоксизамещенные фталоцианины меди из фталонитрилов IV, V в указанных выше условиях синтеза комплексов кобальта VIII, IX нам получить не удалось. Различные результаты при сплавлении солей кобальта и меди с фталонитрилами IV, V вероятно связаны с различной координирующей способностью, размерами ионов этих металлов, а также стерическими факторами.

Представленное на Рисунке 3 геометрическое строение молекул металлокомплексов с тетра(моно- и дисульфонафтокси)замещенными фталоцианинами на основании проведенных квантово-химических расчетов методом AM1 указывают на стерические препятствия для вступления металла в координационную полость фталоцианинового макроцикла, обусловленные объемными сульфонафтоксизаместителями.

Вместе с тем, при совместном сплавлении фталонитрилов (IV или V) и незамещенного фталонитрила в их равных мольных соотношениях с хлоридом одновалентной меди при температуре 190 - $195^{\circ} \mathrm{C}$ из реакционной массы нам удалось выделить соединения, хорошо растворимые в водных растворах щелочей, в смеси ДМФА-вода и имеющие типичные для сульфокислот фталоцианина меди электронные спектры поглощения (Рисунок 4). Основываясь на литературных данных по совместному сплавлению замещенных производных

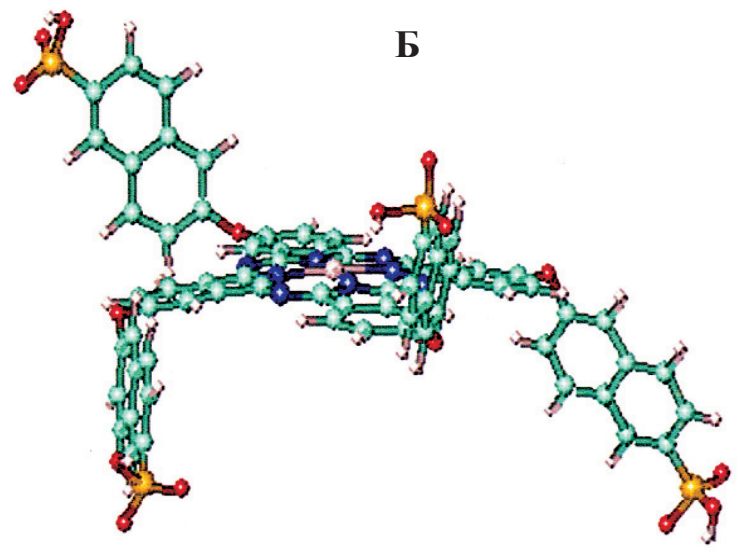

Тетра-4-[(6'-сульфо-2'-нафтил)окси] металлофталоцианин

Рисунок 3. Модель геометрического строения молекул сульфонафтилоксизамещенных фталоцианинов VIII (А), IX (Б) по данным метода АM1. 


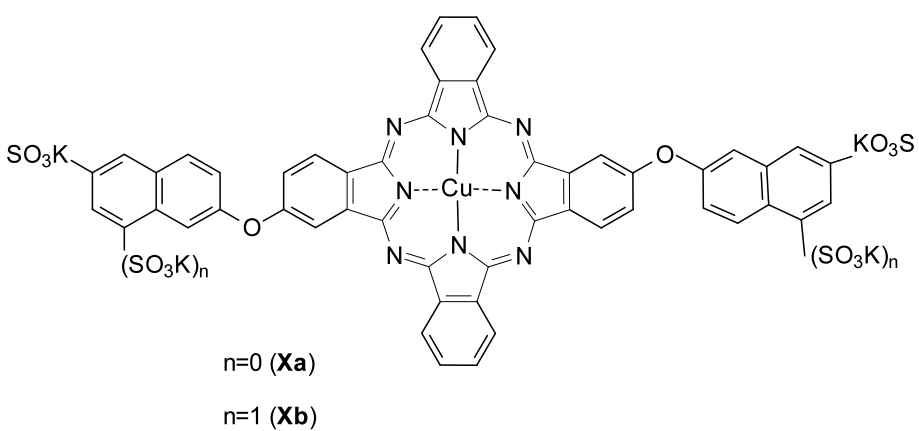

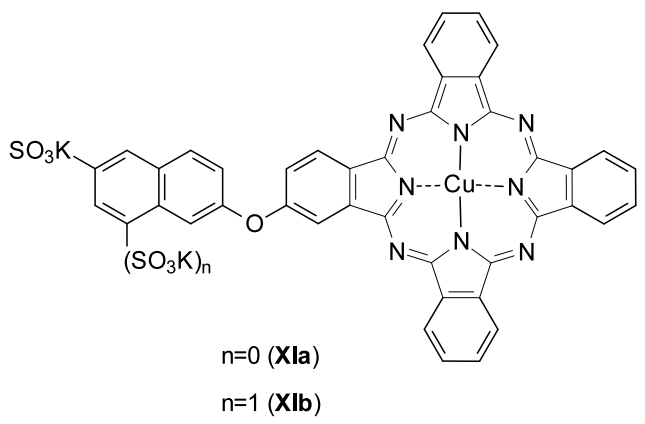

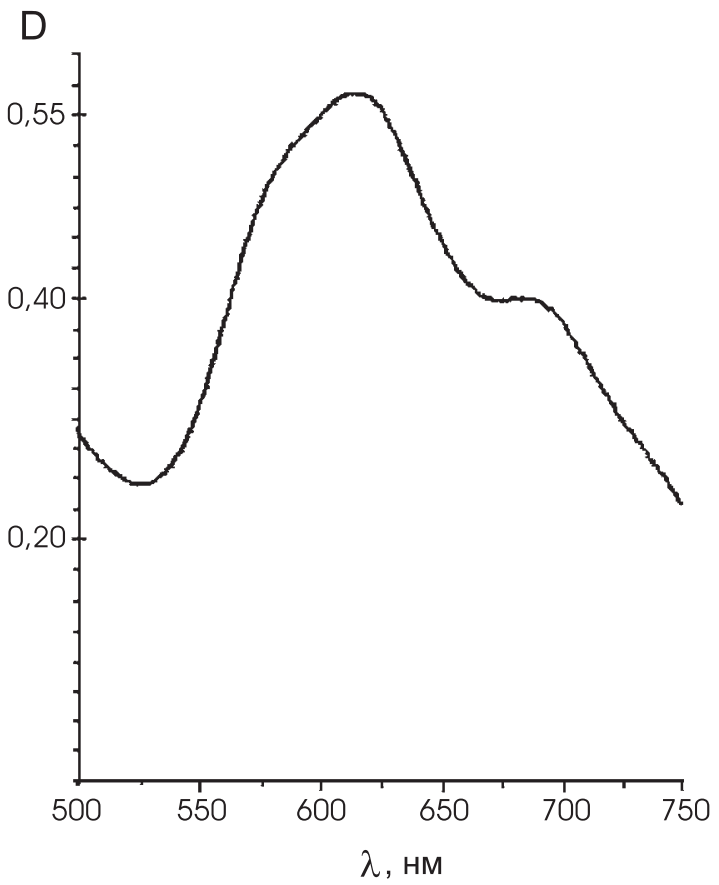

Рисунок 4. Электронный спектр поглощения комплекса меди на основе нитрила $\mathbf{V}$ в $0,5 \%$ растворе $\mathrm{KOH}$.

фталевой кислоты ${ }^{[15]}$ мы предполагаем, что в нашем случае наиболее вероятным является образование следующих комплексов меди (Xa,b - XIa,b).

Получение комплексов с тремя сульфонафтоксизамещенными и одним незамещенным изоиндольным фрагментами, а также изомерных $(\mathbf{X I a , b ) ~ к о м п л е к с о в ~}$ c ияс-расположенными замещенными фрагментами маловероятно из-за отмеченных стерических препятствий. Приведенные на Рисунке 4 ЭСП комплекса меди, полученного из нитрила $\mathbf{V}$ и незамещенного фталонитрила, в 0,5\% растворе $\mathrm{KOH}$ имеют уширенные полосы с максимумом 621 нм и слабовыраженное плечо при 685 нм. Такой характер спектра отмечен ранее при совместном сплавлении с $\mathrm{CuCl}$ 3,5-дисульфофталевой кислоты и фталевого ангидрида. ${ }^{[16]}$

\section{Выводы}

Синтезированы моно- и дисульфонафтоксизамещенные фталонитрилы, на основе которых получены соответствующие замещенные безметальные фталоцианины и комплексы с кобальтом, растворимые в полярных органических растворителях и водных средах. В отличие от кобальта медь не образует комплексов с указанными фталонитрилами, в тоже время комплексы меди образуются при совместном сплавлении сульфонафтоксизамещенного и незамещенного фталонитрила с хлоридом меди.

Строение синтезированных фталонитрилов и фталоцианинов подтверждено данными элементного анализа, ИК и электронной спектроскопии.

\section{Список литературы}

\section{References}

1. Khimiya Sinteticheskikh Krasitelei (Venkataramana K., Ed.). Leningrad: Khimiya, 1977, 5, p. 211-273 (in Russ).

2. Stepanov B.I. Vvedenie v Khimiyu i Tekhnologiyu Organicheskikh Krasitelei. Moskva: Khimiya. 1984, 520-546. (in Russ).

3. Maizlish V.E., Shaposhnikov G.P. Uspekhi Khimii Porfirinov (Golubchikov O.A. Ed.). Sankt-Peterburg: NII Khimii SPbGU, 2004, 4, 327-355 (in Russ).

4. Wöhrle D., Hirth A., Bogdahn-Rai T., Schnurpfeil G., Shopova M. Izv. Ross. Akad. Nauk, Ser. Khim. 1998, 5, 836-842 (in Russ).

5. Lutsenko O.G., Shaposhnikov G.P., Kulinich V.P., Lyubimtsev A.V. Zh. Obshch. Khim. 2004, 74, 491-495 (in Russ).

6. Volkov K.A., Avramenko G.V., Negrimovsky V.M., Luk'yanets E.A. Zh. Obshch. Khim. 2007, 77, 1040-1047 (in Russ.).

7. Abramov I.G. Abstract Diss. Dr. Chem. Sci. Yaroslavl' YTY, 2003, 40 p. (in Russ.).

8. Gordon A., Ford G. Sputnik Khimika Moskva, Mir, 1976,

9. Efimova S.V., Korzhenevsky A.B., Koifman O.I. In: The XXII International Conference Coord. Chem. Kishinev, 2005, 361-302 (in Russ.).

10. Sidorov A.N., Kotlyar I.P. Opt. Spektrosk. 1961, 11, 175-184. (in Russ.).

11. Electronnie Spektri Ftalocianinov i Rodstvennikh Soedinenii (Luk'yanets E.A., Ed.) Cherkassi, NII Khim, 1989, 94 p. (in Russ.).

12. Maizlish V.E., Mochalova N.L., Snegireva F.P., Borodkin V.F. Izv. Vyssh. Uchebn. Zaved., Khim. Khim. Tekhnol. 1986, 29, 3-20 (in Russ).

13. Rollman L.D., Iwamoto R.T. J. Am. Chem. Soc. 1968, 90, 1455-1463.

14. Kulinich V.P., Lebedeva T.A., Borisov A.V., Gorelov V.A., Shaposhnikov G.P. Zh. Obshch. Khim. 2009, 79, $1369-1375$ (in Russ).

15. Kiriyama C., Fukada N. Scn. Rep. Niigata Univ. (C).1971, 3, 9-21.

16. Kulinich V.P., Shaposhnikov G.P., Gorelov V.A., Chernyaeva E.A. Zh. Obshch. Khim. 2006, 76, 1387-1392 (in Russ).

Received 22.10.2009

Accepted 30.01.2010

First published on the web 12.02.2010 200-214 (in Russ.). 